\section{Loyalitas Kreativitas \\ Aldi Masyarakat Kreatif}

P-ISSN 2722-2101, E-ISSN 2722-4201

Program Studi Ekonomi Manajemen Universitas Pamulang

Jurnal LOKABMAS Kreatif Vol. 01, No. 01, Hal. 76 - 82

Email:jurnalkreatif.manajemen@gmail.com

\title{
SOSIALISASI UNDANG-UNDANG PERLINDUNGAN ANAK DAN KDRT KELURAHAN PULAU PANGGANG KABUPATEN KEPULAUAN SERIBU
}

\author{
Yoyon M Darusman, Susanto, RR Dewi Anggraeni, Bachtiar, Bastinaon \\ Dosen Magister Hukum Universitas Pamulang \\ Email : susanto@unpam.ac.id
}

\begin{abstract}
ABSTRAK
Pengabdian ini berjudul Sosialisasi Undang-Undang Perlindungan Anak dan KDRT Kelurahan Pulau Panggang Kabupaten Kepulauan Seribu.

Tujuan pengabdian ini adalah untuk Memberikan materi-materi tentang Undang-Undang Perlindungan Anak dan Undang-Undang KDRT yang berlaku saat ini di dalam sistem hukum Indonesia. Metode pelaksanaan pengabdian ini dilakukan dalam beberapa kegiatan yaitu tahap survei yaitu sosialisasi dilakukan dengan menyusun berbagai hal yang akan disampaikan pada saat kegiatan pengabdian yang akan dilakukan yang meliputi: penyusunan materi yang akan diberikan, penyusunan jadwal pemberian materi, pembagian tugas tim pengabdian dan survei ke lokasi pengabdian. Tahap sosialisasi yaitu sebelum kegiatan pengabdian dilaksanakan terlebih dahulu dilakukan tahap sosialisasi yaitu melakukan silaturahmi dengan ketua yayasan, menyampaikan maksud dan tujuan pengabdian ini. Pada tahap ini juga dilakukan jalinan kerjasama dan menentukan jadwal kegiatan pengabdian. Tim pelaksana kegiatan pengabdian pada masyarakat adalah dosen Fakultas Magister Hukum Universitas Pamulang sebanyak 5 orang. Tim pengabdian memberikan materi tentang pemahaman masyarakat mengenai KDRT dan perlindungan anak..

Kesimpulan dari pengabdian ini adalah Peserta kurang mengerti apa itu dampak psikologi wanita dan anak anak pada kekerasan dalam rumah tangga. Ternyata materi yang berkaitan dengan perlindungan anak sangat diperlukan masyarakat disana berkenaan dengan jarak yang jauh karena hamper semua pulau terpisah
\end{abstract}

Kata Kunci: Sosialisasi, Perlindungan Anak, Kekerasan Dalam Rumah Tangga

\begin{abstract}
ABSTRAC
This dedication is entitled Socialization of the Law on Child Protection and Domestic Violence in Pulau Panggang Village, Kepulauan Seribu District.

The purpose of this service is to provide material about the Child Protection Act and the Domestic Violence Act currently in the Indonesian legal system. The method of implementing this service is carried out in a number of activities, namely the survey stage, namely the socialization carried out by compiling various things that will be delivered at the time of service activities that will be carried out which include: preparation of material to be given, preparation of material delivery schedule, division of tasks of the service team and survey to the location devotion. The socialization phase is before the community service activities are carried out first, the socialization phase is to make a friendship with the chairman of the foundation, conveying the aims and objectives of this service. At this stage also carried out the fabric of cooperation and determine the schedule of service activities. The implementing team of community service activities are 5 lecturers at the Faculty of
\end{abstract}




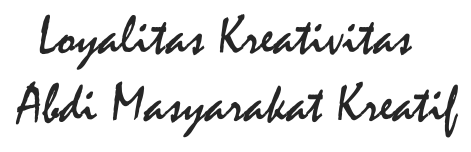

P-ISSN 2722-2101, E-ISSN 2722-4201

Program Studi Ekonomi Manajemen Universitas Pamulang Jurnal LOKABMAS Kreatif Vol. 01, No. 01, Hal. 76 - 82

Email:jurnalkreatif.manajemen@gmail.com

Law at Pamulang University. The dedication team provides material on community understanding of domestic violence and child protection.

The conclusion of this dedication is that participants do not understand what the psychological impact of women and children on domestic violence. It turns out that material relating to child protection is needed by the people there regarding long distances because almost all islands are separated

\section{Keywords: Socialization, Child Protection, Domestic Violence}

\section{PENDAHULUAN}

Perguruan Tinggi berkewajiban untuk melaksanakan Tridharma Perguruan Tinggi sebagaimana yang diamanatkan dalam Undang-Undang Nomor : 12 Tahun 2012 tentang Perguruan Tinggi. Dalam Pasal 1 Ayat (9) dijelaskan bahwa Tridharma Perguruan Tinggi yang selanjutnya disebut Tridharma adalah kewajiban Perguruan Tinggi untuk menyelenggarakan Pendidikan, penelitian, dan pengabdian kepada masyarakat (P3KM). Dosen sebagai salah unsur penting dari perguruan tinggi memiliki kewajiban untuk melaksanakan Tridharma Perguruan Tinggi dalam rangka mentransformasi keilmuan dan intelektualitas, sebagaimana yang disebutkan dalam Pasal 1 Ayat (14) menjelaskan bahwa Dosen adalah pendidik profesional dan ilmuwan dengan tugas utama mentransformasikan, mengembangkan, dan menyebarluaskan Ilmu Pengetahuan dan Teknologi melalui Pendidikan, Penelitian, dan Pengabdian kepada Masyarakat. Salah satu bagian dari Tridharma Perguruan Tinggi sebagai bagian dari kewajiban adalah pengabdian kepada masyarakat, sebagaimana dijelaskan dalam Pasal 1 Ayat (11) bahwa Pengabdian kepada Masyarakat adalah kegiatan sivitas akademika yang memanfaatkan Ilmu Pengetahuan dan Teknologi untuk memajukan kesejahteraan masyarakat dan mencerdaskan kehidupan bangsa.

Hal ini menjadi sangat penting dalam memberikan kontribusi positif dalam membangun kemajuan bangsa dan negara. Universitas Pamulang (Unpam) adalah salah satu Perguruan Tinggi Swasta yang secara konsisten menyelenggarakan P3KM sebagaimana yang diamanatkan oleh Undang-Undang No. 12 Tahun 2012 tentang Perguruan Tinggi, yang dalam pelaksanaannya P3KM di Unpam diselenggarakan oleh Lembaga Penelitian dan Pengabdian Kepada Masyarakat (LP2M). LP2M Unpam memegang peranan yang sangat penting dalam mendorong dan mengarahkan kegiatan-kegiatan penelitian dan pengabdian kepada masyarakat sebagai wujud dari Tridharma Perguruan Tinggi. Setiap pelaksanaan kegiatan P3KM yang diselenggarakan oleh seluruh Program Studi harus berkordinasi dengan LP2M. Dalam hal ini kegiatan pengabdian kepada masyarakat sedang digalakan sebagai bagian dari rangkaian akademik dosen dalam memberikan wawasan dan pemahaman tentang tugas pokoknya sebagai pendidik yang wajib mentranformasikan keilmuannya kepada masyarakat. Program Studi Ilmu Hukum S2 Unpam akan menyelenggarakan PKM ke Kantor Kelurahan Pulau Panggang Kecamatan Kepulauan Seribu Utara Kabupaten Pulau Seribu Provinsi DKI Jakarta, sebagai bagian dari implementasi kerja sama yang selama ini telah terjalin.

Kegiatan PKM dimaksud di dalamnya meliputi sosialisasi UndangUndang Perlindungan Anak dan UndangUndang KDRT yang akan disampaikan kepada para kader PKK dan para petugas Posyandu di lingkungan Kantor Kelurahan Pulau Panggang yang kebetulan sedang melakukan kegiatan kemasyarakatan. Dengan pemberian materi-materi tambahan berupa wawasan tentang Undang-Undang Perlindungan Anak dan Undang-Undang 


\section{Loyalitas Kreativitas \\ Aldi Masyarakat Kreatif}

P-ISSN 2722-2101, E-ISSN 2722-4201

Program Studi Ekonomi Manajemen Universitas

Pamulang

Jurnal LOKABMAS Kreatif Vol. 01, No. 01, Hal. 76 -

82

Email:jurnalkreatif.manajemen@gmail.com

KDRT diharapkan dapat memberikan wawasan dalam pemahaman tentang hukum kepada para peserta kegiatan sosial kem,asyarakatan. Pelaksanaan PKM Program Studi Ilmu Hukum S2 dilaksanakan melibatkan Dosen Tetap, Para Mahasiswa dan Alumni Ilmu Hukum S2.

Adapun biaya pelaksanaan PKM didukung oleh Yayasan Sasmita Jaya dan Swadaya Dosen Tetap pada Prodi Ilmu Hukum S2. Tentunya sinergi keterlibatan pimpinan prodi, dosen tetap, mahasiswa dan alumni diharapkan mampu memberikan nilai tambah dalam memahami bagaimana pentingnya kontribusi nyata dari Perguruan Tinggi kepada masyarakat. Akhirnya, semoga pelaksanaan kegiatan PKM yang dilaksanakan oleh Program Studi Ilmu Hukum S2 bekerja sama dengan Kantor Kelurahan Pulau Panggang Kecamatan Kepulauan Seribu Utara Kabupaten Pulau Seribu Provinsi DKI Jakarta,mampu memberikan kemanfaatan yang nyata kepada Dosen, Mahasiswa dan Alumni tentang bagaimana pentingnya pelaksanaan Tridharma Perguruan Tinggi dan sudah tentu materi-materi yang disampaikan kepada peserta kegiatan sosial kemasyarakatan yang nota bene merupakan bagian dari masyarakat, mampu menambah nilai-nilai keilmuan di bidang hukum khususnya Undang-Undang tentang Perlindungan Anak (UU No. 23 Tahun 2002), Undang-Undang tentang Kekerasan Dalam Rumah Tangga (KDRT-UU No.23 Tahun 2004 ) dan Undang-Undang tentang Peradilan Anak (UU No. 11 Tahun 2012).. "Kekerasan terhadap perempuan" dalam Undang-undang Nomor UU No 23 Tahun 2004 didefinisikan sebagai setiap perbuatan terhadap seseorang terutama perempuan, yang berakibat timbulnya kesengsaraan atau penderitaan secara fisik, seksual, psikologis, dan/atau penelantaran rumah tangga termasuk ancaman untuk melakukan perbuatan, pemaksaan, atau perampasan kemerdekaan secara melawan hukum dalam lingkup rumah tangga. Mirip dengan itu, pengertian "kekerasan terhadap anak" dalam Undang-undang Nomor 35 Tahun 2014 adalah setiap perbuatan terhadap anak yang berakibat timbulnya kesengsaraan atau penderitaan secara fisik, psikis, seksual, dan/atau penelantaran, termasuk ancaman untuk melakukan perbuatan, pemaksaan, atau perampasan kemerdekaan secara melawan hukum. Meski konsekuensi hukumannya cukup berat, dan kalangan pemerintah maupun masyarakat sipil pun telah bekerja keras mengatasinya dengan menghabiskan dana serta sumber daya lainnya yang kian tahun semakin meningkat, namun kasus-kasus kekerasan terhadap perempuan dan anak di negeri ini justru bertambah gawat dan mengkhawatirkan. Sepertinya para pelaku kekerasan itu tidak takut sedikit pun dengan ancaman hukuman. Dalam tahun 2015 saja, menurut Komisi Nasional Perempuan, terjadi sedikitnya 321.752 kasus kekerasan terhadap perempuan, atau rata-rata 881 kasus setiap hari. Dibanding tahun sebelumnya, angka ini meningkat $9 \%$. Sedangkan dalam catatan Komisi Perlindungan Anak Indonesia, pada tahun yang sama, terdapat 1.698 pengaduan kekerasan terhadap anak, 53\% di antaranya ialah kasus kekerasan seksual. Sisanya, yakni sebanyak 40,7\% adalah penelantaran, penganiayaan, eksploitasi seksual, dan berbagai bentuk kekerasan lainnya. Kasuskasus kekerasan pada anak di Indonesia meningkat bukan hanya secara kuantitatif yaitu dari segi jumlah, tetapi juga secara kualitatif yaitu dari segi makin buruknya derajat kekerasan atau intensnya perlakuan yang mereka terima dari pelaku. LPSK (Lembaga Pelindungan Saksi dan Korban) pada awal Januari 2018 merilis pernyataan bahwa kasus kekerasan seksual pada anak meningkat (Republika.co.id, 10 Januari 2018). Ketua Komnas Perlindungan Anak, Aris Sirait, pada Desember 2017 juga menyatakan bahwa dari 2737 kasus dengan 2848 klien yang mereka terima pada 2017, kasus kekerasan seksual merupakan yang 


\section{Loyalitas Kreativitas \\ Aldi Masyarakat Kreatif}

P-ISSN 2722-2101, E-ISSN 2722-4201

Program Studi Ekonomi Manajemen Universitas

Pamulang

Jurnal LOKABMAS Kreatif Vol. 01, No. 01, Hal. 76 -

82

Email:jurnalkreatif.manajemen@gmail.com

terbanyak yaitu sebesar $52 \%$ dari jumlah diatas (Tribun News online, 27 Desember 2017). Hal senada juga disebutkan oleh KPAI yang menyatakan kasus kekerasan seksual pada anak meningkat $100 \%$. Kasuskasus kekerasan terhadap perempuan dan anak merupakan fenomena gunung es. Artinya, kasus yang muncul di permukaan diperkirakan jauh lebih sedikit dibandingkan dengan yang masih terpendam. Tidak terungkapnya kasus tersebut disebabkan beberapa hal, antara lain rasa malu karena tidak mau aib keluarga terbongkar ke publik, dan ancaman dari pihak penganiaya terhadap korban agar bungkam. Perlu sosialisasi yang terus menerus dari Lembaga terkait agar masyarakat makin sadar dan peduli untuk melaporkan kasus-kasus kekerasan keluarga ke pihak-pihak yang berwenang menangani. Lembaga-lembaga ini ada yang langsung berkaitan dengan hukum (Unit Perlindungan Perempuan Anak Kepolisian) dan lembaga-lembaga mediasi yang bertugas menjadi penengah dari konflik keluarga. Di tingkat daerah kabupaten/kota, ada beberapa lembaga yang sudah berdiri, antara lain P2TP2A (Pusat Pelayanan Terpadu Pemberdayaan Perempuan dan Anak), Satgas Anak, dan PATBM (Perlindungan Anak Terpadu Berbasis Masyarakat), dan Puspaga (Pusat Pembelajaran Keluarga). Dalam UU Perlindungan Anak No. 23/ 2002 yang diperbaharui menjadi UU PA No. 35/2014 dan penetapan PERPU No.1/2016 terhadap UU No.35/2014 menjadi UU No. 16/2017, disebutkan bahwa Pemerintah bertanggungjawab terhadap perlindungan anak yang kemudian dilakukan oleh pemerintah daerah di wilayahnya masingmasing.

\section{TUJUAN PELAKSANAAN}

Memberikan materi-materi tentang Undang-Undang Perlindungan Anak dan Undang-Undang KDRT yang berlaku saat ini di dalam sistem hukum Indonesia

\section{TINJAUAN PUSTAKA}

1. Kekerasan Dalam Rumah Tangga (KDRT)

Kekerasan dalam rumah tangga (disingkat KDRT) adalah tindakan yang dilakukan di dalam rumah tangga baik oleh suami, istri, maupun anak yang berdampak buruk terhadap keutuhan fisik, psikis, dan keharmonisan hubungan sesuai yang termaktub dalam pasal 1 UU Nomor 23 tahun 2004 tentang Penghapusan Kekerasan dalam Rumah Tangga (UU PKDRTHak Cipta (copyright);

Yang merupakan lingkup tindakan KDRT adalah perbuatan terhadap seseorang terutama perempuan, yang berakibat timbulnya kesengsaraan atau penderitaan

secara fisik, seksual, psikologis,

dan/atau penelantaran rumah tangga termasuk ancaman untuk melakukan perbuatan, pemaksaan, atau perampasan kemerdekaan secara melawan hukum dalam lingkup rumah tangga. Sebagian besar korban KDRT adalah kaum perempuan (istri) dan pelakunya adalah suami, walaupun ada juga korban justru sebaliknya, atau orang-orang yang tersubordinasi di dalam rumah tangga itu. Pelaku atau korban KDRT adalah orang yang mempunyai hubungan darah, perkawinan, persusuan, pengasuhan, perwalian dengan suami, dan anak bahkan pembatu rumah tangga yang tinggal dalam sebuah rumah tangga. Tidak semua tindakan KDRT dapat ditangani secara tuntas karena korban sering menutup-nutupi dengan alasan ikatan struktur budaya, agama, dan belum dipahaminya sistem hukum yang berlaku. Padahal perlindungan oleh negara dan masyarakat bertujuan untuk memberi rasa aman terhadap korban serta menindak pelakunya 


\section{Loyalitas Kreativitas \\ Aldi Masyarakat Kreatif}

P-ISSN 2722-2101, E-ISSN 2722-4201

Program Studi Ekonomi Manajemen Universitas

Pamulang

Jurnal LOKABMAS Kreatif Vol. 01, No. 01, Hal. 76 -

82

Email:jurnalkreatif.manajemen@gmail.com

Pengertian manajemen secara umum dapat disimpulkan dari beberapa definisi menurut para ahli. Hal ini karena ada banyak versi definisi manajemen. Misalnya saja manajemen menurut seorang ahli bernama Mary Parker Follet yang mendefinisikan manajemen sebagai seni merampungkan pekerjaan melalui orang lain. Dari definisi tersebut didapati bahwa seseorang yang bertugas sebagai manajer dapat mengarahkan dan mengatur orang lain guna mencapai tujuan organisasi.

\section{Perlindungan Anak}

Anak merupakan tunas, potensi, dan generasi muda penerus cita-cita perjuangan bangsa, memiliki peran strategis dan mempunyai ciri dan sifat khusus yang menjamin kelangsungan eksistensi bangsa dan negara di masa depan. Hak Asasi Anak merupakan bagian dari hak asasi manusia yang termuat dalam Undang-undang Dasar Negara Republik Indonesia tahun 1945 dan Konvensi perserikatan bangsabangsa tentang Hakhak Anak.Ketentuan Pasal 28B ayat (2) Undang-Undang Dasar Negara Republik Indonesia menyebutkan bahwa setiap anak berhak atas kelangsungan hidup, tumbuh dan berkembang serta berhak atas perlindungan dari kekerasan dan diskriminasi.

Konvensi hak Anak secara khusus mengatur segala sesuatu tentang hak anak. Konvensi Hak Anak tersebut mulai beriaku pada tanggai 2 September 1990 melalui revolusi Perserikatan Bangsa-Bangsa tertanggal 20 Nopember 1989 dan sesuai dengan ketentuan konvensi PasaI 49 ayat (1). Dalam konvensi ini anak adalah pemegang hak-hak dasar dan kebebasan sekaligus sebagai pihak yang menerima perlindungan khusus. Konvensi Hak Anak ini juga lahir dari suatu kesadaran bahwa anak sesuai dengan kodratnya adalah rentan, tergantung. lugu, dan memiliki kebutuhan-kebutuhan khusus. Oleh karena itu pula anak memerlukan perawatan dan perlindungan yang khusus, baik fisik maupun mental. Indonesia pada tahun 1990 telah meratifikasi Konvensi hak Anak tersebut berdasarkan Keputusan Presiden Nomor 36 Tahun 1990 tertanggal 25 Agustus 1990. sesuai dengan ketentuan konvensi Pasal 49 ayat (2), maka Konvensi hak Anak dinyatakan berlaku di Indonesia sejak tanggaI 5 Oktober 1990. Sebagai konsekuensinya "seharusnya" Pemerintah Indonesia berkewajiban untuk semaksimal mungkin berupaya memenuhi hakhak anak di Indonesia. Undang-Undang Nomor 39 Tahun 1999 tentang Hak Asasi Manusia dalam Bab III Hak Asasi Manusia dan Kebebasan Dasar Manusia pada Bagian Kesepuluh mengatur mengenai hak anak. Bagian yang mempunyai judul Hak Anak ini memberikan ketentuan pengaturan yang dituangkan ke dalam 15 (lima belas) pasal, dimana dalam Pasal 52 ayat (2) disebutkan bahwa hak anak adalah hak asasi manusia dan untuk kepentingannya hak anak itu diakui dan dilindungi oleh hukum bahkan sejak dalam kandungan. Negara Kesatuan Republik Indonesia dalam menjamin kesejahteraan pada setiap warga negaranya salah satunya adalah dengan memberikan perlindungan terhadap hak anak yang merupakan salah satu dari hak asasi manusia. Pemerintah Indonesia dalam usahanya untuk menjamin dan mewujudkan perlindungan dan kesejahteraan anak adalah melalui pembentukan UndangUndang Nomor 23 Tahun 2002 tentang Perlindungan Anak. Dan dalam rangka 


\section{Loyalitas Kreativitas \\ Aldi Masyarakat Kreatif}

P-ISSN 2722-2101, E-ISSN 2722-4201

Program Studi Ekonomi Manajemen Universitas

Pamulang

Jurnal LOKABMAS Kreatif Vol. 01, No. 01, Hal. 76 -

82

Email:jurnalkreatif.manajemen@gmail.com

penyesuaian terhadap beberapa ketentuan maka dilakukan beberapa perubahan terhadap pasal-pasal tertentu maka diundangkan Undang-Undang nomor 35 Tahun 2014 tentang perubahana atas Undang-Undang Nomor 23 Tahun 2002 tentang Perlindungan Anak. Perlindungan Anak tersebut adalah segala kegiatan untuk menjamin dan melindungi anak dan hak-haknya agar dapat hidup, tumbuh, berkembang, dan berpartisipasi secara optimal sesuai dengan harkat dan martabat kemanusiaan, serta mendapat perlindungan dari kekerasan dan diskriminasi. Perlindungan anak terkait erat dengan lima pilar yakni, orang tua, keluarga, masyarakat, pemerintah, pemerintah daerah dan negara. Kelimanya memiliki keterkaitan satu sama lain sebagai penyelenggara perlindungan anak. Dalam bentuknya yang paling sederhana, perlindungan anak mengupayakan agar setiap hak anak tidak dirugikan. Perlindungan anak bersifat melengkapi hak-hak lainnya menjamin bahwa anak-anak akan menerima apa yang mereka butuhkan agar mereka dapat bertahan hidup, berkembang dan tumbuh. Akan tetapi pada kenyataannva kondisi anakanak di Indonesia masih sangat memprihatinkan terutama yang menyangkut masalah pekerja anak, anak jalanan, dan anak-anak korban kekerasan seksual, eksploitasi seksual, dan eksploitasi seksual komersial.

\section{METODE PELAKSANAAN}

Metode pelaksanaan pengabdian ini dilakukan dalam beberapa kegiatan yaitu tahap survei yaitu sosialisasi dilakukan dengan menyusun berbagai hal yang akan disampaikan pada saat kegiatan pengabdian yang akan dilakukan yang meliputi: penyusunan materi yang akan diberikan, penyusunan jadwal pemberian materi, pembagian tugas tim pengabdian dan survei ke lokasi pengabdian. Tahap sosialisasi yaitu sebelum kegiatan pengabdian dilaksanakan terlebih dahulu dilakukan tahap sosialisasi yaitu melakukan silaturahmi dengan ketua yayasan, menyampaikan maksud dan tujuan pengabdian ini. Pada tahap ini juga dilakukan jalinan kerjasama dan menentukan jadwal kegiatan pengabdian. Tim pelaksana kegiatan pengabdian pada masyarakat adalah dosen Dosen Pascasarjana Magister Hukum Universitas Pamulang sebanyak 5 orang. Tim pengabdian memberikan materi tentang Sosialisasi Undang-Undang Perlindungan Anak dan KDRT Kelurahan Pulau Panggang Kabupaten Kepulauan Seribu.

\section{HASIL DAN PEMBAHASAN}

Pengabdian Masyarakat (LPPM) Universitas Pamulang yang dilakukan oleh dosen-dosen program studi Manajemen telah berjalan dengan lancar dan mendapat sambutan hangat dari tempat pelaksanaan kegiatan ini yaitu di Kelurahan Pulau Panggang Kabupaten Kepulauan Seribu.

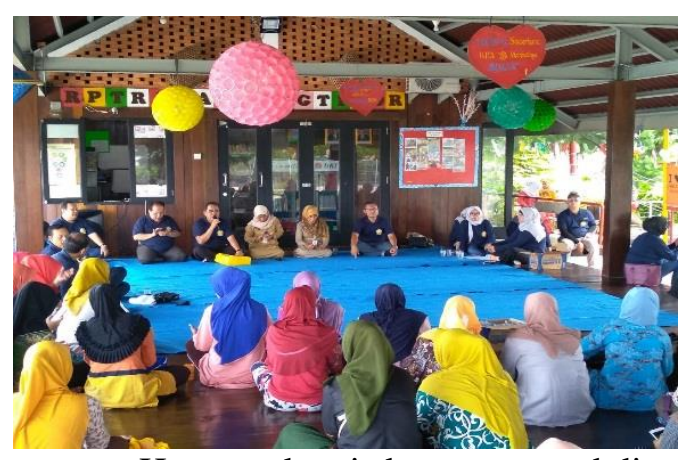

Harapan kami dengan pengabdian ini dapat membuka wawasan masyarakat yang diperoleh adalah bertambahnya keilmuan bagi para Para Masyarakat tentang Perlindungan Anak dan KDRT.

\section{KESIMPULAN DAN SARAN}




\section{Loyalitas Kreativitas \\ Aldi Masyarakat Kreatif}

P-ISSN 2722-2101, E-ISSN 2722-4201

Program Studi Ekonomi Manajemen Universitas

Pamulang

Jurnal LOKABMAS Kreatif Vol. 01, No. 01, Hal. 76 -

82

Email:jurnalkreatif.manajemen@gmail.com

Kesimpulan

Ternyata materi yang berkaitan dengan perlindungan anak sangat diperlukan masyarakat disana berkenaan dengan jarak yang jauh karena hamper semua pulau terpisah.

Saran

Sehubungan dengan jarak dengan ibuko jauh, transportasi sulit maka kegiatan perlu dilakukan secara berkeseinambungan.

\section{DAFTAR PUSTAKA}

Darusman, Y. M., Susanto, S., Anggraeni, R. D., Gueci, R. S., \& Yanto, O. (2019). Penyuluhan Peraturan PerundangUndangan Pemilihan Umum (PEMILU) Tahun 2019 (Studi Kasus pada Politeknik Ilmu Pemasyarakatan (POLTEKIP) Kementerian Hukum dan HAM RI, Depok, Jawa Barat). Jurnal Abdi Masyarakat Humanis, 1(1).

Iqbal, M. I., Susanto, S., \& Sutoro, M. (2019). Functionalization of E-Court System in Eradicating Judicial Corruption at The Level of Administrative Management. Jurnal Dinamika Hukum, 19(2), 370-388.

Susanto, M. I. (2019). Kedudukan Hukum People Power dan Relevansinya dengan Hak Kebebasan Berpendapat di Indonesia. Volksgeist: Jurnal Ilmu Hukum dan Konstitusi, 2(2), 225-237.

Susanto, S. (2019). EKSEKUSI PUTUSAN TANPA HADIRNYA TERGUGAT (Studi Kasus CV. Global Mandiri Sejahtera). RECHTSREGEL Jurnal Ilmu Hukum, 1(2).

Susanto, S., \& Bastianon, B. (2020). FUNGSI INVESTIGATIF DALAM KEBEBASAN HAKIM MEMUTUS PERKARA YANG DIDASARKAN PADA PENERAPAN HUKUM PEMBUKTIAN. jURNAL SURYA
KENCANA DUA DINAMIKA MASALAH HUKUM DAN KEADILAN, 6(2).

Susanto, S., \& Halim, I. (2020, January). PENGARUH HUMAN RELATION DAN LINGKUNGAN KERJA TERHADAP KINERJA KARYAWAN PADA PT. KOMPAS GRAMEDIA CABANG KARAWACI. In PROCEEDINGS (Vol. 1, No. 1).

Susanto, S., \& Iqbal, M. (2019). Pengabdian Kepada Masyarakat Dalam Sinergitas Akademisi Dan TNI Bersama Tangkal Hoax Dan Black Campaign. CARADDE: Jurnal Pengabdian Kepada Masyarakat, 2(1), 8-16.

Zulfitra, Z., Susanto, S., Mubarok, A., Sutoro, M., \& Anwar, S. (2019). Manajemen Bisnis Sebagai Sarana Untuk Menumbuhkan Pengusaha-Pengusaha Baru (Studi Kasus pada PKBM Nurul Qolbi, Kota Bekasi, Jawa Barat). Jurnal Abdi Masyarakat Humanis, 1(1).

\section{DOKUMENTASIFOTO KEGIATAN}
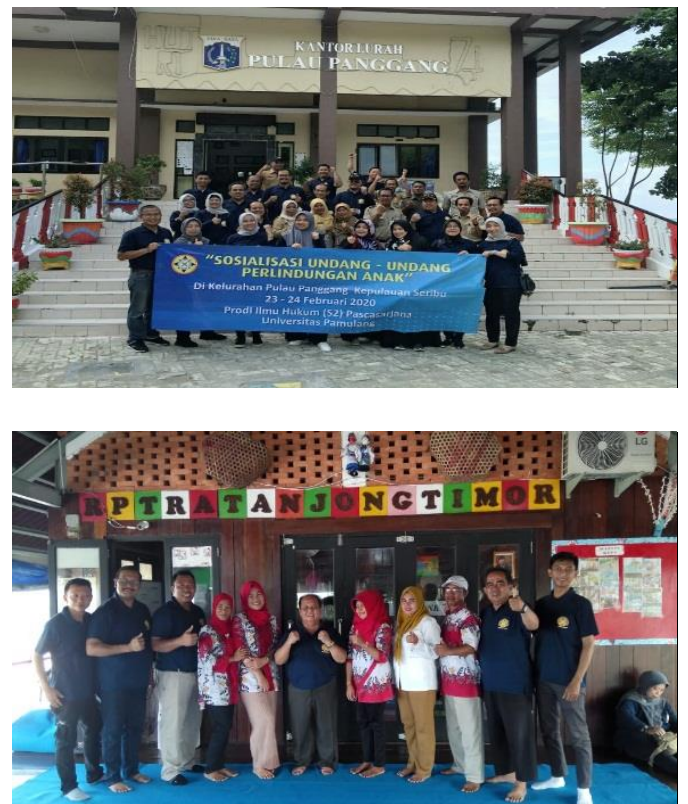
Loyalitas Kreativitas

Aldi Masyarakat Kreatif
P-ISSN 2722-2101, E-ISSN 2722-4201

Program Studi Ekonomi Manajemen Universitas

Pamulang

Jurnal LOKABMAS Kreatif Vol. 01, No. 01, Hal. 76 -

82

Email:jurnalkreatif.manajemen@gmail.com

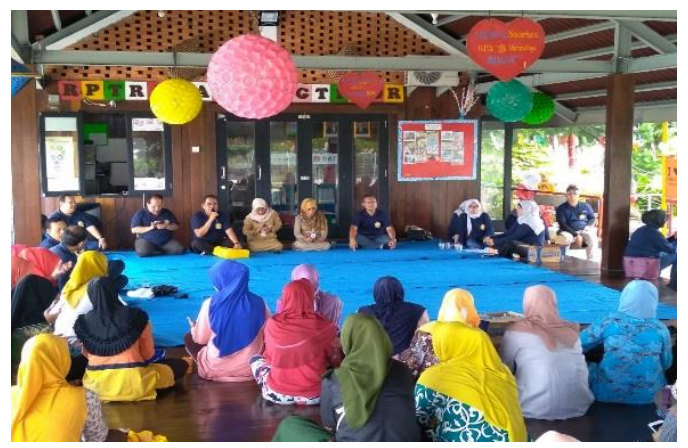

